\title{
Dissimilar Laser Welding of AISI 321 and AISI 1010
}

\author{
Elena Manuela STANCIU, Alexandru PASCU, Mircea Horia TIEREAN, Ionut Claudiu ROATA, Ionelia VOICULESCU, Iosif HULKA, \\ Catalin CROITORU
}

\begin{abstract}
This paper presents the dissimilar laser welding of AISI 321 stainless steel and AISI 1010 carbon steel thin sheets in butt joint geometry using a $1 \mathrm{~kW}$ diode laser. Influence of the welding speed on the geometry and microstructure of the joints is discussed. Structural characterisation of the welds is realised through optical, electron microscopy and EDS analysis, observing distinct mixed and unmixed areas in the weld bead because of the high cooling rate. The weld bead presents an austenitic-martensitic-ferrite structure, characterized by austenitic twin grains with ferrite particles precipitated on grain boundaries, and islands comprising a ferritemartensite structure. Chromium and nickel migration in the weld bead area was observed. Good tensile behaviour of the dissimilar joints was obtained, as all the specimen failure occurs far-off the weld zone.
\end{abstract}

Keywords: dissimilar welding; laser; microhardness; stainless steel; tensile behaviour

\section{INTRODUCTION}

Current research in laser welding aims at joining a large category of structurally dissimilar materials, such as thin stainless steel, titanium, copper or aluminium components, which are otherwise difficult to be joined using the traditional welding methods.

Due to the high local energy concentration of the laser beam, laser technology is by far the most suitable method for stainless steel welding. Chromium precipitation on the grain boundaries is avoided by using a high laser welding speed that diminishes the exposure of the weld to high temperatures. Stainless steel is used in a plenitude of domains from low end applications, like sanitary products to high-end applications like aerospace industry [1 - 4].

Nowadays, due to economic considerations, stainless steel is frequently used in dissimilar welds configurations such as stainless steel - alloyed steel, carbon steel, copper, titanium. Stainless steel-carbon steel dissimilar joints (known as black and white joints $[5,6]$ ) are widely used for manufacturing of chemical installations, in power generation installations, as well as in the petrochemical, nuclear and automotive industries [7 - 10].

Regarding the joining of dissimilar materials, such as in the case of stainless steel-carbon steel laser welding, the structural and operational key factors involved are represented by differences in terms of alloying elements, surface reflectivity, heat conductivity rate and thermal expansion coefficients for the joined materials.

Different types of heterogeneous welds that involve stainless steel are recently reported in the literature. Khan et al. concluded that laser power and incident beam angle is the key factor that determines the weld bead geometry in the process of AISI 304 and AISI 340 dissimilar laser welding [11]. Dissimilar laser spot welds between low carbon and austenitic stainless steels are carried out by Torkamany with good results in terms of tensile-shear monotonic loading [12]. A more challenging investigation, welding of AISI 420 stainless steel to kovar alloy, through minimizing hot crack formation in the weld zone is reported by Baghjari [13]. Good results were obtained by Mousavi for laser welding of AISI 321 and AISI 630 stainless steels in a circular but weld geometry [14]. By using controlled experimental conditions regarding the laser power, Anawa obtained good results in terms of mechanical proprieties of ferritic/austenitic (F/A) joints [15].

Another aspect to be taken into consideration for the stainless steel-carbon steel welded couple is the formation of delta ferrite phase, more susceptible to grain boundary corrosion as well as of a residual austenite phase [16] due to the fast cooling of the metal bath that leads to an incomplete $\delta-\gamma$ transformation [2, 4, 17], phenomena which are more pronounced with the decreasing of materials thickness.

Up to date, due to the complexity of the domain, there are relatively few studies regarding physical and mechanical behaviour of stainless steel welding in a dissimilar configuration.

There are steel combinations which have not been sufficiently studied due to the multitude of factors that influence the weld quality. The present study aims to study the dissimilar laser welding between the AISI 321 stainless steel and AISI 1010 carbon steel. Weld bead geometry, microstructure and tensile behaviour of the joints are analysed.

\section{EXPERIMENTAL PROCEDURE \\ 2.1 Materials}

The welding tests were performed on $50 \times 100 \times 0.5$ $\mathrm{mm}$ specimens of AISI1010 and AISI 321 commercial steel. AISI 1010 (CS) is a low carbon steel and is commonly used in the automotive or construction industry.

The AISI 321 (SS) is commercial titanium stabilised austenitic stainless steel. Addition of Ti in the chemistry of AISI 321 is useful in ensuring a high resistance of steel parts to surface oxidation, as well as in preventing the inter-granular corrosion and the chromium carbide precipitation at the grain boundary during the welding processes.

The chemical content of the materials used in the welding studies is presented in Tab. 1.

\subsection{Laser Welding Procedure}

The experimental tests have been performed by using a Coherent F1000 diode laser, at $\lambda=975 \mathrm{~nm}$ with a peak power of $1000 \mathrm{~W}$ and a maximum divergence of 56 
$\mathrm{mm} \times \operatorname{mrad}$ for the incident beam. The laser beam was focused to a diameter of $0.7 \mathrm{~mm}$ by a Precitec YW 50 welding head manipulated by a CLOOS Quirox welding robot
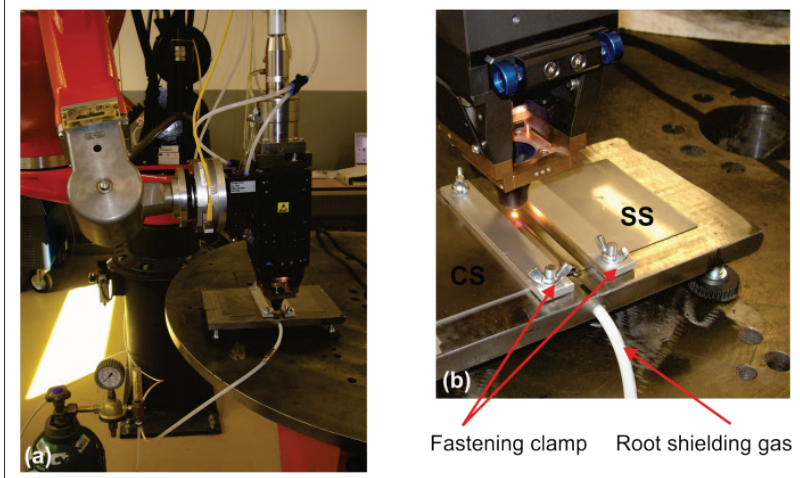

Figure 1 (a) Experimental set-up used for the laser welding tests, (b) close-up of positioning and fastening device

Positioning and fastening of the sheets has been performed employing a special designed device (see Fig. 1(b)). For the protection of the weld bead root, $4 \mathrm{l} / \mathrm{min}$ argon has been purged through a specially designed channel placed at the bottom interface of the sheets. The superior part of the melted metal bath was shielded with $99.98 \%$ vol. argon at a constant flow of $101 / \mathrm{min}$. The CS-SS laser welds were carried out without using any filler material. For the protection of the laser optics a $5^{\circ}$ tilt of the welding head in the welding direction was used. The experimental frame used for the dissimilar laser welding is presented in Fig. 1a and $1 \mathrm{~b}$.

The process parameters used for the CS-SS dissimilar welding are summarised in Tab. 2. The input variable of the welding tests was the welding speed. Gradual increasing of the welding speed and maintaining the same power was used in order to emphasize the influence of the parameters on to the weld geometry. It has been determined through several preliminary experimental tests that $550 \mathrm{~W}$ is the minimum laser power that provides penetration in the range of $160-200 \mathrm{~cm} / \mathrm{min}$ welding speed.

The laser beam was positioned more on the stainless steel plate and less on the carbon steel due to the lower thermal conductivity and higher reflectivity of the stainless steel.

Table 1 The chemical elemental composition of the welded steel types

\begin{tabular}{|c|c|c|c|c|c|c|c|c|c|}
\hline \multirow{2}{*}{ Material } & \multicolumn{9}{|c|}{ Element wt. (\%) } \\
\hline & $\mathrm{C} \%$ & $\mathrm{Si} \%$ & $\mathrm{Mn} \%$ & $\mathrm{P} \%$ & S \% & $\mathrm{Cr} \%$ & $\mathrm{Ni} \%$ & Mo \% & $\mathrm{Ti} \%$ \\
\hline AISI 1010 & 0.099 & 0.168 & 0.51 & 0.0033 & 0.0069 & 0.043 & 0.041 & 0.0024 & - \\
\hline AISI 321 & 0.08 & 1 & 2 & 0.045 & 0.03 & 18 & 11 & - & 0.15 \\
\hline
\end{tabular}

Table 2 Experimental conditions and response factors

\begin{tabular}{|c|c|c|c|c|c|c|}
\hline & & \multicolumn{5}{|c|}{ Sample } \\
\hline Parameters & Units & 3.1 & 3.2 & 3.3 & 3.4 & 3.5 \\
\hline Laser power & W & 550 & 550 & 550 & 550 & 550 \\
\hline Power density & $\mathrm{kW} / \mathrm{cm}^{2}$ & 143 & 143 & 143 & 143 & 143 \\
\hline Energy density & $\mathrm{J} / \mathrm{mm}^{2}$ & 29.4 & 27.7 & 26.2 & 24.8 & 23.5 \\
\hline Welding speed & $\mathrm{cm} / \mathrm{min}$ & 160 & 170 & 180 & 190 & 200 \\
\hline Weld penetration & $\mathrm{mm}$ & 0.51 & 0.50 & 0.51 & 0.37 & 0.30 \\
\hline Weld bead width & $\mathrm{mm}$ & $\begin{array}{l}1.19 \\
0.69\end{array}$ & $\begin{array}{l}1.14 \\
0.54\end{array}$ & $\begin{array}{l}1.09 \\
0.47\end{array}$ & $\begin{array}{c}1.07 \\
-\end{array}$ & $\begin{array}{c}1.05 \\
-\end{array}$ \\
\hline Weld bead area & $\mathrm{mm}^{2}$ & 0.41 & 0.36 & 0.33 & 0.25 & 0.19 \\
\hline
\end{tabular}

The power density and the energy density are calculated as follows [18]:

$$
\begin{aligned}
& P_{\mathrm{d}}=\frac{P}{A_{\mathrm{s}}}, \\
& E_{\mathrm{d}}=\frac{P}{v \cdot A_{\mathrm{s}}},
\end{aligned}
$$

where: $P_{\mathrm{d}}$ is the laser power density $\left(\mathrm{kW} / \mathrm{cm}^{2}\right), E_{\mathrm{d}}$ is the laser energy density $\left(\mathrm{J} / \mathrm{mm}^{2}\right), P$ is the laser power $(\mathrm{kW}), v$ is the welding speed $(\mathrm{cm} / \mathrm{mm})$ and $A_{\mathrm{s}}$ is the laser spot area $\left(\mathrm{cm}^{2}\right)$.

The welded samples have been cut and prepared by using a standardized method and further electrochemically etched with $10 \%$ solution of oxalic acid for the SS and Nital 1.5\% reagent for the CS.

An Olympus GX51 optical microscope - and a Quanta Inspect $\mathrm{F}$ electron microscope at $30 \mathrm{kV}$ were used for metallographic analyses.
The EDS analyses have been realised using a Quanta FEG 250 electron microscope, equipped with EDAX analyser - FEI.

\section{RESULTS AND DISCUSSION 3.1 Weld Bead Profile}

To obtain the best tensile behaviour as well as minimizing the heat affected zone, a complete penetration of thin sheets butt welds is required in case of industrial applications of welded components. As shown in Fig. 2, full and partial penetration has been obtained in case of CS-SS laser welding. The geometrical profile of the weld bead shows that a proper correlation between the welding speed and power density is necessary to obtain complete penetration (sample 3.1, 3.2, 3.3).

Information regarding the minimum laser energy necessary for a correct weld bead profile was obtained by maintaining the same laser power and a constant increasing of the welding speed by approx. $6 \%$. 

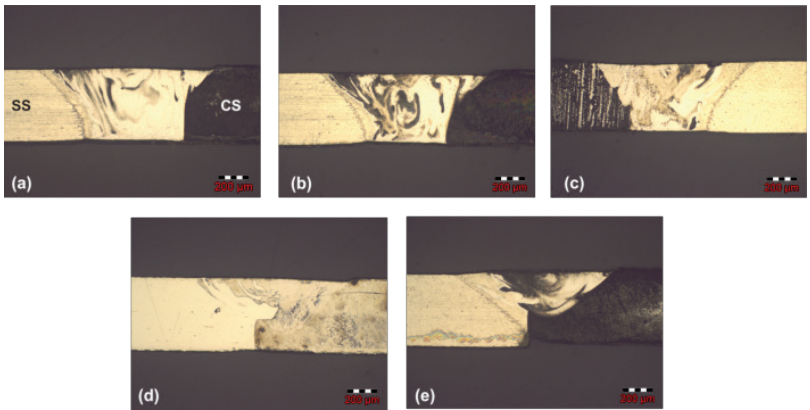

Figure 2 Low magnification cross-section of CS-SS laser welding; (a) sample 3.1, (b) sample 3.2, (c) sample 3.3, (d) sample 3.4, (e) sample 3.5

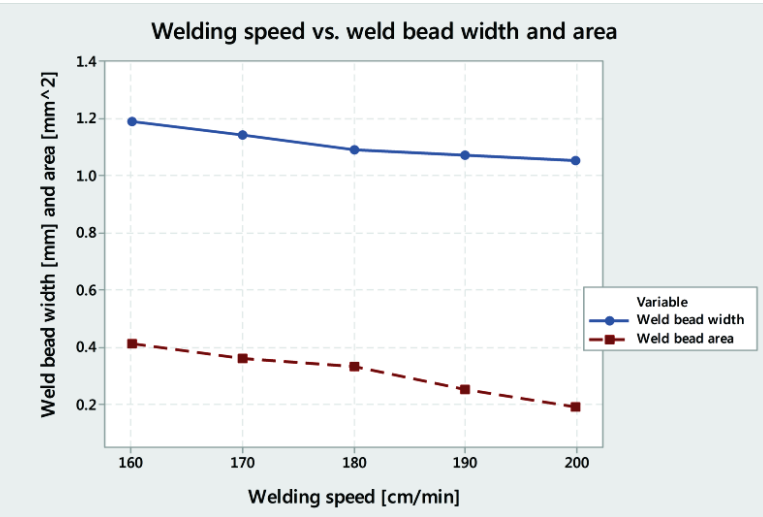

Figure 3 Relationship between the welding speed and the weld bead profile

Fig. 3 represents the dependence between the welding speed and the weld bead width and area indicating that weld bead area decreases sharply at a welding speed above $180 \mathrm{~cm} / \mathrm{min}$. This result indicates that a minimum energy of $26 \mathrm{~J} / \mathrm{mm}^{2}$ is necessary to obtain a full penetration welding of $0.5 \mathrm{~mm}$ dissimilar sheets. In the micrographs from Figs. 4 and 5 the heterogeneous structure formed in the dissimilar joint could be observed.

The weld bead microstructure is composed by mixed and unmixed regions due to the high cooling rate of the weld zone. Strong non homogeneity regions with distinct areas rich in ferrite alternating with areas of mixed austenitic-martensitic-ferrite microstructures are revealed in Fig. 4a.

\subsection{Microstructure}

The general microstructure of the dissimilar joints could be formed by an austenitic-martensitic- ferrite structure, determined by the SS, characterized by austenitic twin grains with ferrite particles precipitated on grain boundaries and carbon steel with ferrite - pearlite structure. At the interface with the base materials there is a boundary fusion zone (unmixed zone, partially mixed zone, intermediate mixed zone or non-interference zone as it is known from reference literature studies [19]) which is different in terms of structure and dimension depending on its location (near CS or near the SS side. In both cases the fusion boundary has a different structure from the weld area and the base materials. It could be observed that large amount of CS constituents (darker area) are present near the boundary with the SS and larger area rich in $\mathrm{Cr}$ and $\mathrm{Ni}$ are present near the interface with the carbon steel (Figures $2 \mathrm{~b}$ and $3 \mathrm{a}$ ). A ferrite structure mixed with pearlite is found in the region adjacent to the carbon steel.
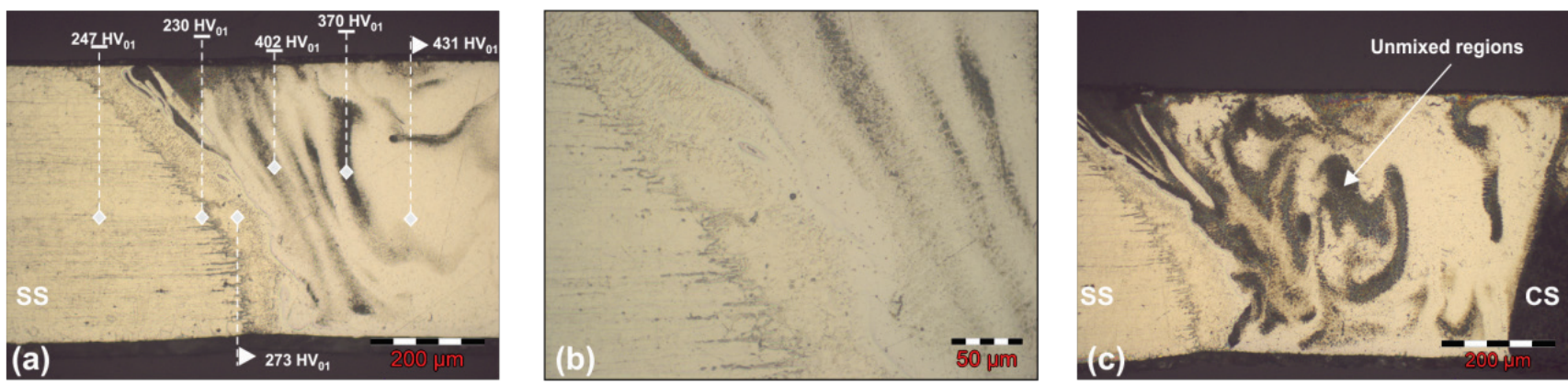

Figure 4 Optical micrograph at the interface of stainless steel - weld bead and hardness distribution at the interface with the SS

The boundary zone near the AISI 321, as shown in Fig. 4 , is formed by a needle like epitaxial growth region with twin structure of austenite - ferrite. An unexpected result is the presence in this area of unmixed region with a high content of iron. The epitaxial growth shows that the mixing of the dissimilar components was not completed during the melting-solidification process, being potentiated in this particular case by the high cooling rate accentuated by the shielding gas provided at the root of the weld.

The solidification pattern determined by columnar growth from the weld zone perpendicular to the stainless steel base material is illustrated in Figs. 5a and 5b. In this boundary zone between the WZ and SS can be observed the lamellar ferrite stringers that resist to austenite transformation during cooling. The weld zone microstructure is formed by an austenitic matrix with residual $\delta$-ferrite and with incomplete formation of widmanstatten austenite.

In Fig. 6a one can observe the distinct darker regions that indicate a large amount of iron from the carbon steel, besides whiter areas with a high content of nickelchromium. The ferrite branches enveloped by the austenite matrix are presented in the high magnification micrograph from Fig. 6b.The microstructure changes from fine equiaxed ferrite in the middle of the weld bead to an oriented skeletal ferrite morphology at the interface with the carbon steel (Fig. 6c).

The fine dendritic morphology presented in the weld bead increases the overall mechanical proprieties of the joint by enhancing the ductility. 

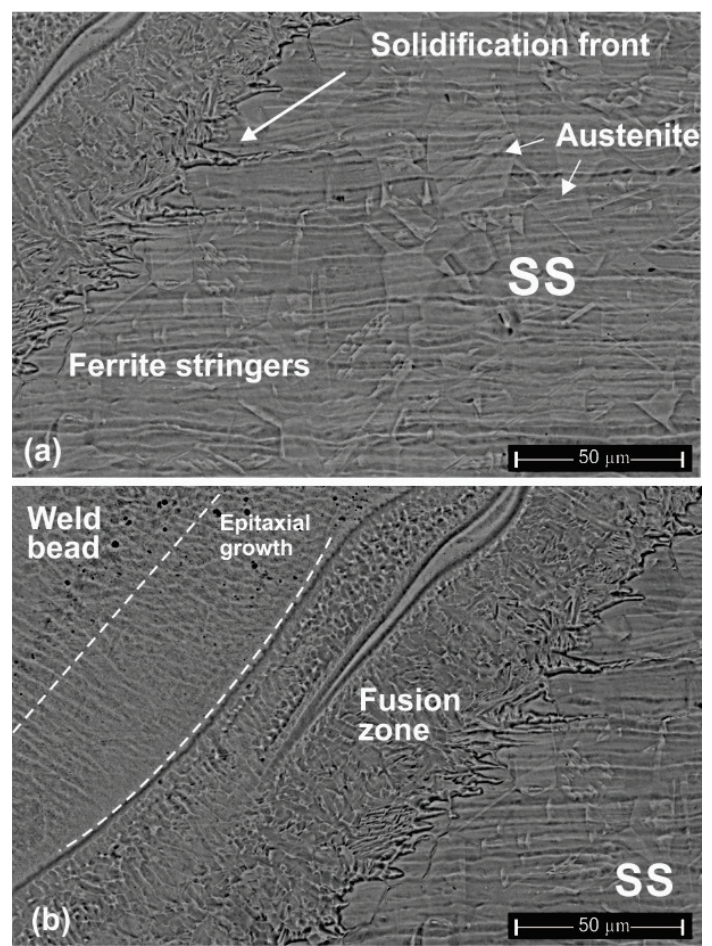

Figure 5 SEM microscopy of the fusion zone on the stainless steel side
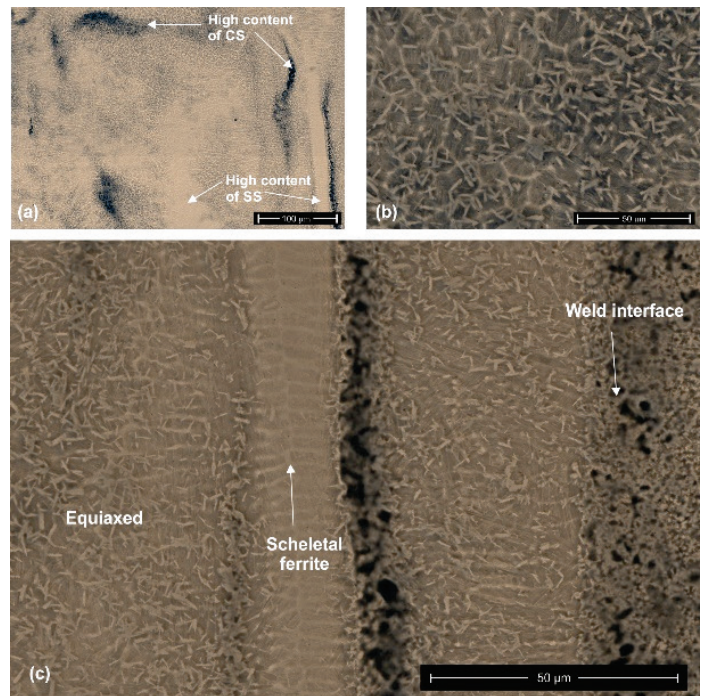

Figure 6 SEM microscopy of the sample 3.2 cross-section, (a) weld interface at CS side, (b) details of the ferrite branches in austenite matrix, (c) higher magnification of weld interface at CS side

The unmixed regions appear as islands of high content ferrite from carbon steel that were melted and resolidified in the entire mass of the weld zone with or without minimal dilution with the weld bead matrix. These unmixed regions are more pronounced near the interface with the base materials.
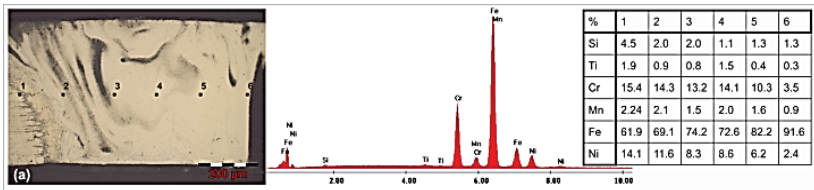

Figure 7 (a) Distribution of the 6 microzones punctually analysed on the crosssection of the 3.1 sample, (b) Energy-Dispersive X-ray spectrum EDS of sample 3.1 microzone 2

The chemical analysis in the microzones from Fig. 7a underlines the distribution of the main alloying components along the weld bead cross section. Because of the high non-homogeneity of the weld bead, the local chemical analysis was repeated 3 times and the medium data values were considered.

As the studied zones are closer to the boundary with the base materials, a change in the weld bead composition emerges due to the diffusion phenomena potentiated by the temperature. It is observed that alloying elements $\mathrm{Cr}$, $\mathrm{Ni}$, Ti diffuses from stainless steel into the weld bead and a pronounced diffusion of iron from CS towards the entire weld joint is produced. As the investigated area is closer to the low alloy steel the constant decreasing of $\mathrm{Ni}$ and $\mathrm{Cr}$ can be observed. EDS results show that in case of the sample welded with a lower energy density (sample 3.3, 3.4 ) the iron diffusion in the weld bead was not as pronounced as in the case of sample 3.1 and 3.2. Fig. 8 underlines by chromatic contrast the distribution of the iron and chromium on the 3.1 sample cross-section profile.
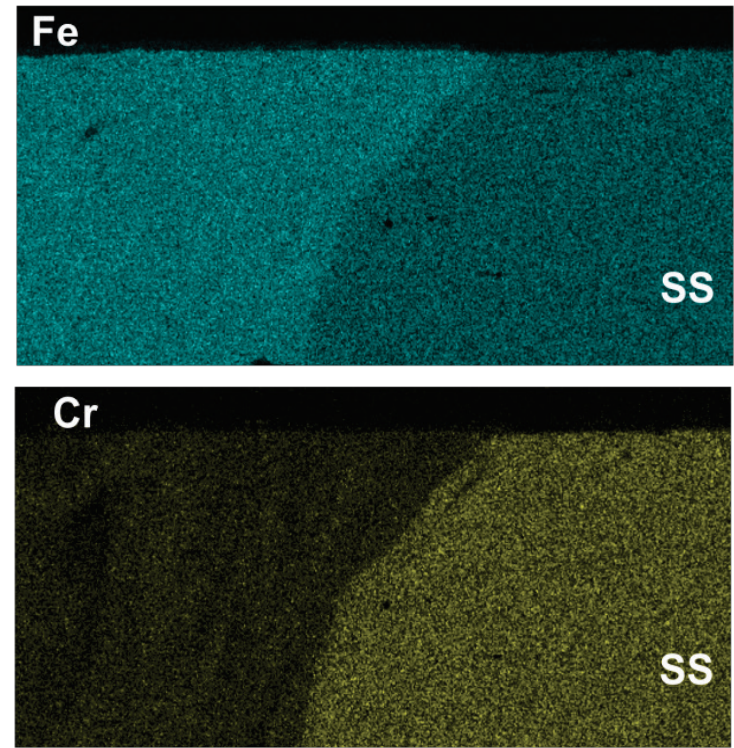

Figure 8 EDS mapping of iron and chromium content on the sample 3.1 at the interface with the SS

The EDS mapping shows the chemical distribution at the interface with the stainless steel. It could be clearly observed that the weld joint has a higher content of iron compared to the SS and a decreased value of chromium, which could be responsible for the low brittleness and the good tensile behaviour of the samples, outlined in Figs. 9 and 10 .

\subsection{Hardness and Tensile Behaviour}

The microhardness testing was performed on a Future-Tech FM-700 tester. The set-up test was a load of $100 \mathrm{gf}$ and 10 second dwell time. Four indentations were made on each particular area of the weld joint. Because of the high non-homogeneity of the weld bead, the hardness analysis was performed twice in each area.

In the graphical representation from Fig. 8 is presented the microhardness profile of the sample 3.1, 3.2 and 3.3. The graph shows that weld zone and heat affected zone both have an increased hardness compared to base materials. One can observe that the heat affected 
zone near the carbon steel has high hardness compared with similar zone from the stainless steel side. It is an unexpected result considering that stainless steel has a higher hardness $\left(248 \mathrm{HV}_{01}\right)$ compared to the CS (160 $\left.\mathrm{HV}_{01}\right)$. Also, a pronounced decreasing of hardness $(250$ $\mathrm{HV}_{01}$ ) was registered in the fusion zone of the $\mathrm{SS}$ side. This hardness decreasing in the fusion zone (Fig. 5b) indicates that because of the high cooling rates the austenite phase was replaced by a ferrite-austenite microstructure characterised by low hardness. Similar results were obtained by Mousavi [14]. On the carbon steel side, the hardness increasing in the HAZ is produced by the transformation of the ferrite-pearlite into martensite structure due to the high thermal gradient. An iron enrichment of the fusion zone near the CS side combined with a high content of $\mathrm{Ni}, \mathrm{Cr}$, may lead to hard $\mathrm{FeNi} / \mathrm{CrNiFe}$ phases formation evidenced by the higher hardness obtained in this area.

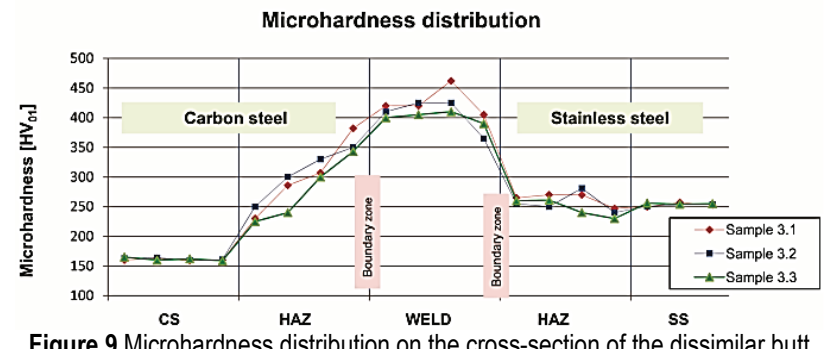

Figure 9 Microhardness distribution on the cross-section of the dissimilar butt welding of AISI 1010 and AISI 321

According to Fig. 9 it should be noted that hardness profile is similar to all the studied samples. A slight decreasing of micro-hardness can be observed at sample 3.3. As the sample was realised with the lowest heat input it may be concluded that hardness profile is influenced by the energy density.

The tensile behaviour of the dissimilar joints was determined by using a servo-hydraulic universal testing machine with a set-up crosshead speed of $10 \mathrm{~mm} / \mathrm{s}$ at room temperature. The transverse tensile tests were performed on specimens of $15 \mathrm{~mm}$ wide and $120 \mathrm{~mm}$ long. All the tensile testing samples were fractured on the carbon steel side far away from the HAZ or welded joint. All the specimens were fractured at $3.1 \mathrm{kN}$ load and $15 \%$ elongation.
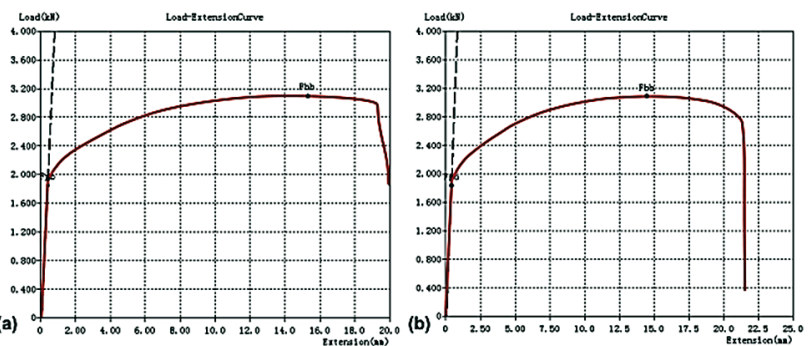

Figure 10 Stress-strain curves of dissimilar welded samples 3.1(a) and 3.4(b)

Fig. 10 shows the stress-strain curve obtained on specimen 3.1 and 3.4. In both cases a good tensile behaviour was obtained considering that sample 3.4 (Fig. $10 \mathrm{~b})$ has only a partial penetration.

\section{CONCLUSIONS}

In this study the effects of the laser welding speed on the geometry and microstructure of dissimilar joints have been studied. Dissimilar thin sheets of $0.5 \mathrm{~mm}$ thickness comprising stainless steel and respectively carbon steel could be successfully welded by laser by using energy density between 26 and $29 \mathrm{~J} / \mathrm{mm}^{2}$. A proper ratio between laser power and welding speed had to be ensured in order to achieve full penetration into the material and a reduced heat affected zone.

The weld bead microstructure is composed of strong non homogeneity regions with distinct areas rich in ferrite alternating with areas of mixed austenitic-martensiticferrite microstructures. The fusion zone microstructure is characterised by ferrite branches enveloped by the austenite matrix towards the stainless steel side and by a non-interference zone at the carbon steel side.

As the power energy decreases, a decreasing of the unmixed area occurs. The lower iron content in the weld bead is determined by the EDS spectrum and by the decreasing of the hardness. In the case of dissimilar welding of AISI 1010 and AISI 321 the hardness profile is determined by the amount of iron diffused from the carbon steel, which could form intermetallic phases with the alloying elements, leading to an overall increase in hardness. As the iron content is higher, the hardness increase will occur due to the formation of hard phases like $\mathrm{FeNi} / \mathrm{CrNiFe}$.

The dissimilar joints present a good tensile behaviour with an ultimate tensile strength similar to the carbon steel mechanical characteristics.

\section{Acknowledgments}

This work was supported by a grant of the Romanian National Authority for Scientific Research and Innovation, CNCS/CCCDI -UEFISCDI, project number PN-III-P2-2.1-BG-2016-0349, within PNCDI III. The characterization of the materials was supported by the Transilvania University of Brasov scholarship for international mobilities.

\section{REFERENCES}

[1] Lo, K. H., Shek, C. H., \& Lai, J. K. L. (2009). Recent developments in stainless steels. Materials Science and Engineering - R: Reports 65(4-6), 39-104. https://doi.org/10.1016/j.mser.2009.03.001

[2] John, C. I. (2005). Laser processing of engineering materials, Elsevier Butterworth-Heinemann, Oxford, UK.

[3] Lima, A. S., Nascimento, A. M., Abreu, H. F. G., \& de Lima-Neto, P. (2005). Sensitization evaluation of the austenitic stainless steel AISI 304L, 316L, 321 and 347. Journal of Materials Science, 40(1), 139-144. https://doi.org/10.1007/s10853-005-5699-9

[4] Yan, J., Gao, M., \& Zeng, X. (2010). Study on microstructure and mechanical properties of 304 stainless steel joints by TIG, laser and laser-TIG hybrid welding. Optics and Lasers in Engineering, 48, 512-517 https://doi.org/10.1016/j.optlaseng.2009.08.009

[5] Iordachescu, D., Scutelnicu, E., Iordachescu, M., Valiente, A., Hervias, J. R., \& Ocaña, J. L. (2011). Specific properties of ferritic/austenitic dissimilar metals welded joints. Welding in the World, 55(3-4), 2-11. 
https://doi.org/10.1007/BF03321280

[6] Iordachescu, D., Blasco, M., Lopez, R., Cuesta, A., Iordachescu, M., \& Ocaña, J. L. (2011). Recent achievements and trends in laser welding of thin plates. Journal of Optoelectronics and Advanced Materials, 13(8), 981-985.

[7] Mishra, D., Vignesh, M. K., Ganesh Raj, B., Srungavarapu, P., Ramkumar, K. D., Arivazhagan, N., \& Narayanan, S. (2014). Mechanical Characterization of Monel 400 and 316 Stainless Steel Weldments. Procedia Engineering, 75, 2428. https://doi.org/10.1016/j.proeng.2013.11.005

[8] Lippold, J. C. \& Kotechki, D. J. (2005). Welding Metallurgy and Weldability of Stainless Steels. John Wiley and Sons, New Jersey, USA.

[9] Klimpel, A. \& Lisiecki, A. (2007). Laser welding of butt joints of austenitic stainless steel AISI 321. Journal of Achievements in Materials and Manufacturing Engineering, 25(1), 63-66.

[10] Stanciu, E. M., Pascu, A., \& Roată, I. C. (2014). Lap joint laser welding of austenitic stainless steel thin sheets. Advanced Materials Research, 1029, 134-139. https://doi.org/10.4028/www.scientific.net/AMR.1029.134

[11] Khan, M. M. A., Romoli, L., Fiasch, M., Dini, G., \& Sarri, F. (2012). Laser beam welding of dissimilar stainless steels in a fillet joint configuration. Journal of Materials Processing Technology, 4(212), 856-867. https://doi.org/10.1016/j.jmatprotec.2011.11.011

[12] Torkamany, M. J., Sabbaghzadeh, J., \& Hamedi, M. J. (2012). Effect of laser welding mode on the microstructure and mechanical performance of dissimilar laser spot welds between low carbon and austenitic stainless steels. Materials and Design, 34, 666-672. https://doi.org/10.1016/j.matdes.2011.05.024

[13] Baghjari, S. H. \& Akbari Mousavi, S. A. A. (2014) Experimental investigation on dissimilar pulsed Nd:YAG laser welding of AISI 420 stainless steel to kovar alloy. Materials and Design, 57, 128-134. https://doi.org/10.1016/j.matdes.2013.12.050

[14] Akbari Mousavi, S. A. A. \& Sufizadeh, A. R. (2009). Metallurgical investigations of pulsed Nd:YAG laser welding of AISI 321 and AISI 630 stainless steels. Materials and Design, 30(8), 3150-3157. https://doi.org/10.1016/j.matdes.2008.11.026

[15] Anawa, E. M. \& Olabi, A. G. (2008). Optimization of tensile strength of ferritic/austenitic laser-welded components. Optics and Lasers in Engineering, 46(8), 571577. https://doi.org/10.1016/j.optlaseng.2008.04.014

[16] Arivazhagan, N., Surendra, S., Satya P., \& Reddy, G. M. (2011). Investigation on AISI 304 austenitic stainless steel to AISI 4140 low alloy steel dissimilar joints by gas tungsten arc, electron beam and friction welding. Materials and Design, 32(5), 3036-3050. https://doi.org/10.1016/..matdes.2011.01.037

[17] Khan, M. M. A., Romoli, L., Fiaschi, M., Dini, G., \& Sarri, F. (2012). Laser beam welding of dissimilar stainless steels in a fillet joint configuration. Journal of Materials Processing Technology, 212(4), 856-867. https://doi.org/10.1016/j.jmatprotec.2011.11.011

[18] Pascu, A. (2013). Parameters of the laser cladding process, LUXLibris Publishing House, Brasov, Romania.

[19] Naffakh, H., Shamanian, M., \& Ashrafizadeh, F. (2009). Dissimilar welding of AISI 310 austenitic stainless steel to nickel-based alloy Inconel 657. Journal of materials processing technology, 209(7), 3628-3639. https://doi.org/10.1016/j.jmatprotec.2008.08.019

\section{Contact information:}

Elena Manuela STANCIU, Assist. Prof. Eng. PhD Transilvania University of Brasov,

Department of Materials Engineering and Welding,

Colina Univeristatii, 1, Brasov, Romania

Email: elena-manuela.stanciu@unitbv.ro

Alexandru PASCU, Assoc. Prof. Eng. PhD

Transilvania University of Brasov,

Department of Materials Engineering and Welding,

Colina Univeristatii, 1, Brasov, Romania

Email: alexandru.pascu@unitbv.ro

Mircea Horia TIEREAN, Prof. Eng. PhD

Transilvania University of Brasov,

Department of Materials Engineering and Welding,

Colina Univeristatii, 1, Brasov, Romania

Email:m.tierean@unitbv.ro

Ionut Claudiu ROATA, Researcher Eng. PhD

Transilvania University of Brasov,

Department of Materials Engineering and Welding,

Colina Univeristatii, 1, Brasov, Romania

Email: r.i.claudiu@gmail.com

Ionelia VOICULESCU, Prof. Eng. PhD

Politehnica University of Bucharest

Faculty of Engineering and Management of Technological Systems

Splaiul Independentei, 313, Bucharest, Romania

Email: ioneliav@yahoo.co.uk

losif HULKA, Researcher Eng. PhD

Polytechnic University of Timisoara,

Victoriei Sqare, 2, 300006, Timişoara, Romania

Email: hulka_iosif@yahoo.com

Catalin CROITORU, Assoc. Prof. Chem. PhD

Transilvania University of Brasov,

Department of Materials Engineering and Welding,

Colina Univeristatii, 1, Brasov, Romania

Email: c.croitoru@unitbv.ro 